\title{
Brain Carbohydrate Metabolism during Experimental Haemophilus influenzae meningitis
}

\author{
E. RICHARD MOXON, ARNOLD L. SMITH, ${ }^{(51)}$ AND DAMON R. AVERILL \\ Department of Pediatrics, Eudowood Division of Infectious Diseases, The Johns Hopkins University School of \\ Medicine, Baltimore, Maryland; and Division of Infectious Diseases and Department of Neuropathology, Children's \\ Hospital Medical Center, Boston, Massachusetts, USA
}

\begin{abstract}
Summary
Five-day-old infant rats which acquire Haemophilus influenzae b bacteremia and meningitis after intranasal inoculation have a transient depression in weight gain ( 2 days), but then continue to grow at the same rate as strain $\mathrm{U}-11$ inoculated controls. Brain lactate, glucose, and glycogen concentrations increase during the first 5 days of disease in infected animals. The increase in brain glycogen can be accounted for by an influx of glycogen containing polymorphonuclear leukocytes. The increased concentrations of glucose and lactate were found not to be due to a change in brain weight to dry weight ratio or the volume of entrapped blood. The mean cerebrospinal fluid (CSF) glucose concentration was higher in animals with meningitis $(2.7 \mathrm{mM})$ in comparison to U-11 inoculated controls $(1.8 \mathrm{mM})$. This increase in brain and CSF glucose concentration appeared secondary to an increased brain uptake of hexoses as manifested by an increased $\left[{ }^{3} \mathrm{H} \mid\right.$ mannitol uptake. Brain lactate accumulation was not explicable from the data available. There was no evidence of cerebral cortical cellular damage because in vitro oxygen uptake and lactate production were equivalent in control and meningitic animals. The ability of the infant rat brain to maintain cerebral adenosine triphosphate (ATP) content in meningitis and the failure of CSF glucose concentration to decrease might be a reflection of the importance of alternative oxidative substrate (e.g., $\beta$-hydroxybutyrate) to the cerebral metabolism of the developing rat brain.
\end{abstract}

\section{Speculation}

Infant rats surviving $H$. influenzae meningitis have on maturation deficits in the acquisition of a learned Skinnerian paradigm, and have reduced cortical dendritic arborization and complexity. With an increased cerebral and CSF glucose content and a normal ATP content during meningitis, the genesis of these lesions may not involve cerebral glucose uptake or oxidative metabolism. Alterations in delivery of substrates to the brain (e.g., cerebral blood flow) or the effect of bacterial products (such as endotoxin) or leukocytes on nervous tissue metabolism might be more profitable areas for future investigations. Any data, however, derived from study of this species should not be directly extrapolated to humans.

Antibiotics have greatly improved the prognosis of bacterial meningitis decreasing the case-fatality rate from 90 (1) to $10 \%$. Ninety-five percent of children with $H$. influenzae meningitis survive (16) largely as a result of appropriate antibiotic therapy. Enthusiasm for the improved survival rate is tempered with the knowledge that neurologic sequelae occur frequently. Studies have indicated that $50 \%$ of long-term survivors of $H$. influenzae b meningitis display varying degrees of cerebral cortical dysfunction $(40,43)$ without overt anatomic lesions. However, the pathophys- iology of postmeningitic central nervous system sequelae is poorly understood.

Hypoglycorrachia is observed in patients with pyogenic meningitis. Its mechanism is unclear, but it has been suggested that it results from abnormal cerebral glucose metabolism (23). In dogs with experimental pneumococcal meningitis the passive diffusion of mannitol from blood into CSF was increased 16-fold; however, net facilitated inward diffusion of 3-O-methylglucose was decreased, as was 3-O-methylglucose efflux. The methods used did not permit net balance studies, but the role of the brain in regulating CSF glucose concentration was not excluded. Because hypoglycemia or subarachnoid hemorrhage can be associated with abnormal cerebral glucose metabolism and is associated with permanent neurologic sequelae, we investigated cerebral carbohydrate metabolism in infant rats with $H$. influenzae meningitis.

These studies utilized an experimental model of $H$. influenzae, type $b$, meningitis in infant rats in which the infection is produced by noninvasive intranasal inoculation of bacteria (27). The occurrence of meningitis can be predicted by the presence of bacteremia $48 \mathrm{hr}$ postinoculation at a density of $>10^{4}$ colony-forming units $/ \mathrm{ml}$ (26). In this model the histopathologic characteristics and CSF inflammatory response simulate those occurring in the human (26, 27). In addition, postmeningitic survivors show a decreased rate of acquisition of operant conditioning (42) and decreased synaptogenesis and dendritic arborization (5). This species was chosen for study recognizing that the results will not be directly extrapolated to man. However, the data may provide insight into the meningitis-induced metabolic derangements in an animal with histologic and functional deficits.

\section{MATERIALS AND METHODS}

The strains of $H$. influenzae, encapsulated type b (strain E-1) and an untypable (strain U-11), the media used for their growth, the growth and quantitation of bacteria, and the rats (SpragueDawley, strain COBS/CD from Charles River Laboratory, Inc., Wilmington, MA) were identical to those used previously $(3,27$, 42).

Body weight, wet and dry brain weight, blood and brain concentration of glucose, lactate, and $\beta$-hydroxybutyrate (BOHB), brain concentrations of glycogen and ATP, and CSF concentration of glucose were measured at intervals after intranasal inoculation of 5-day-old rats with $H$. influenzae. This information was obtained by performing several similar experiments.

Five-day-old infant rats were weighed and inoculated intranasally with $10^{7}$ strain E-1 or U-11. Strain U-11 produces neither bacteremia nor histologic abnormality of the central nervous system $(27,42)$. Therefore, $U-11$ inoculated rats served as controls.

Animals were killed at $1,2,3,5,7$, or 9 days after inoculation. Animals with bacteremia $>10^{4} / \mathrm{ml}$ were assumed to have meningitis in those experiments which prohibited analysis of the CSF; brain tissue analyses from these animals were compared to controls. Animals were weighed daily, including the day of killing. 
Wet and dry weight of brain were measured after removal from the decapitated skull. The whole brain was weighed in a clean, dry beaker and dessicated at $100^{\circ}$ to a constant weight.

To measure blood and brain labile metabolites, animals were killed by rapid decapitation allowing the heads to fall into liquid nitrogen. Simultaneously $0.1 \mathrm{ml}$ whole blood was added to $0.9 \mathrm{ml}$ cold $\left(4^{\circ}\right) 3.5 \%$ perchloric acid (PCA) (Alfa Inorganics, Beverly, MA), mixed, and centrifuged for $10 \mathrm{~min}$ at $6,000 \times g$ at room temperature. The PCA supernatant was used to determine the blood concentration of glucose, lactate, and $\mathrm{D}(-)$-BOHB. Glucose was determined using the glucose oxidase method (33). Absorbance was recorded on a Guilford spectrophotometer at $400 \mathrm{~nm}$. BOHB was measured using the method of Antonis et al. (4) and lactate by the method described by Neville and Gelder (29), using a Beckman Acta III spectrophotometer. Fluorometry was performed using a Turner fluorometer, model 111 (G. K. Turner Associates, Palo Alto, CA). ATP was measured using the method of Cheer et al. (7). Frozen skulls were removed after $2 \mathrm{~min}$ in liquid nitrogen. Approximately $300 \mathrm{mg}$ cortex was dissected from the frozen brain, weighed, and added to $2.5 \mathrm{ml}$ cold $3.5 \%$ PCA, insonated for $3 \mathrm{~min}$ at 60 watts (Branson no. 20) in a bath chilled to $-5^{\circ}$, and centrifuged for $1 \mathrm{hr}$ at $10,000 \times \mathrm{g}$ at $0-4^{\circ}$. The resulting clear supernatant was used to measure the cortical concentration of glucose, lactate, BOHB, and ATP.

Brain glycogen measurements required a different technique of preparation: frozen brain $\left(-70^{\circ}\right)$ was placed in absolute ethanol at $-20^{\circ}$ (U. S. Industrial Chemical Co.). After 4 days at $-20^{\circ}$, the brain tissue was allowed to warm to $25^{\circ}$. Approximately $300 \mathrm{mg}$ cortex was weighed and added to $5 \mathrm{ml} 0.03 \mathrm{~N}$ hydrochloric acid. This was insonated for $3 \mathrm{~min}$ at 60 watts in a $-5^{\circ}$ bath. One-tenth of a milliliter of the homogenate was used to determine brain glycogen concentration employing the enzymatic method of Passonneau et al. (31).

In one experiment involving six animals, the frozen skulls were divided sagitally after $2 \mathrm{~min}$ in liquid nitrogen. One hemi-skull was used to measure glycogen concentration and the other was processed for light microscopy. In a parallel experiment six bacteremic rat pups (2 days postinoculation) were perfused under ether anesthesia with paraformaldehyde-glutaraldehyde solution containing $0.1 \mathrm{M}$ phosphate buffer at $\mathrm{pH} 7.4$ (5). Twenty-five percent and $50 \%$ solutions were administered in succession into the left cardiac ventricle under a pressure of $120 \mathrm{~cm} \mathrm{H}_{2} \mathrm{O}$. The right atrium was lacerated to allow venous blood to drain and the perfusions were continued until his outflow was clear. Approximately $12 \mathrm{~min}$ was necessary to allow $25 \mathrm{ml}$ fixative at each concentration to perfuse the animals.

The brains were removed and placed in 50\% fixative for $2 \mathrm{hr}$ and stored in $0.1 \mathrm{M}$ phosphate buffer ( $\mathrm{pH} \mathrm{7.4)}$ overnight. Coronal $0.1-\mathrm{cm}$ slices were made through the right frontal lobes $0.5 \mathrm{~cm}$ caudal to the frontal pole and a $0.1-\mathrm{cm}$ block was removed $0.2 \mathrm{~cm}$ lateral to the dorsal longitudinal fissure. This block was postfixed in $1.0 \% \mathrm{OsO}_{4}$ for $2 \mathrm{hr}$, embedded in Epon, sectioned to sliver interference thickness with a glass knife, and stained with uranyl acetate and lead citrate before examination with the electron microscope. Adjacent sections were prepared for light microscopy and stained with hematoxylin and eosin. Glycogen was identified as free, round, electron-dense nonmembrane-bound cytoplasmic particles averaging $300 \AA$ in diameter (36).

Brain-blood content was measured at 2 and 7 days after inoculation using a modification of the method of Gordon and Nurnberger $(14,15)$. Animal heads were decapitated into liquid nitrogen and frozen as noted above, $0.01 \mathrm{ml}$ venous blood was obtained for quantitative culture, and duplicate $0.05-\mathrm{ml}$ samples were obtained for hemoglobin determination. Approximately $300 \mathrm{mg}$ frozen cerebral cortex was dissected in a $-20^{\circ}$ cold room, weighed, and homogenized in phosphate-buffered saline $(2 \mathrm{ml} / \mathrm{g}$ brain) with a standard clearance Potter-Elvehjem homogenizer for $1 \mathrm{~min}$. The homogenate was then isonated at 50 watts at $0^{\circ}$ for $2 \mathrm{~min}$. Brain hemoglobin content was determined by adding $0.2 \mathrm{ml}$ sonified homogenate to $1.5 \mathrm{ml}$ Drabkins reagent (10) and recording the optical density at $540 \mathrm{~nm}$. Cyanmethoglobin standard curves were constructed by reacting known concentrations of crystalline rat hemoglobin (Schwartz-Mann twice recrystallized, Orangeburg, NY) with Drabkins reagent. This method probably overestimates the brain-blood content because of the presence of other heme proteins whose cyano derivatives absorb at $540 \mathrm{~nm}$ (e.g., cytochromes). Brain-blood content was calculated for each animal from blood and brain hemoglobin concentration.

Brain hexose uptake was studied in rats 3 days after intranasal inoculation with $H$. influenzae. At this time, nine rats with bacteremia at a density $>10^{4} / \mathrm{ml}$ and nine controls were given an ip injection of $0.9 \%$ saline $(20 \mathrm{ml} / \mathrm{kg})$ containing [ $\left.{ }^{3} \mathrm{H}\right]$ mannitol, 4 $\mu \mathrm{Ci} / \mathrm{ml}$, (New England Nuclear, Boston, MA) and 3-O-[methyl$\left.{ }^{14} \mathrm{C}\right] \mathrm{D}$-glucose, $1.7 \mu \mathrm{Ci} / \mathrm{ml}$, (New England Nuclear). After 120 min, the rats were decapitated allowing the heads to fall into liquid nitrogen and blood was obtained from the severed vessels. The blood was kept on ice until it clotted, after which it was centrifuged at $6000 \times g$ for $30 \mathrm{~min}$. A $50-\mu \mathrm{l}$ serum sample was transferred to PCA (3.5\%), mixed, centrifuged, and neutralized with $0.26 \mathrm{ml} 3 \mathrm{M} \mathrm{K}_{2} \mathrm{CO}_{3}$. A $0.5-\mathrm{ml}$ aliquot was counted in $3 \mathrm{ml}$ dioxane using a Packard Tricarb counter adjusted to discriminate between ${ }^{14} \mathrm{C}$ and ${ }^{3} \mathrm{H}$ with internal standards. Approximately 300 $\mathrm{mg}$ frozen cerebral cortex was insonated in 3.5\% PCA as described for metabolite measurements. The acid extract was assayed as described for the serum sample.

Oxygen uptake by rat cortex was measured on bacteremic rats and controls at $3,5,10$, and 20 days after inoculation. Brains were rapidly dissected from the decapitated intact skull. The cortex was separated from the rest of the brain, blotted free of surface blood, weighed, and placed on the platform of a McIlwain tissue chopper (22) and the surface was covered with a few drops of ice-cold Krebs-Ringer phosphate (KRP). The total time taken from killing to this stage was less than $2 \mathrm{~min}$. The brain was minced into squares measuring $3 \mathrm{~mm} \times 3 \mathrm{~mm}$ using the micrometer adjustment setting on the McIlwain tissue chopper. Brain slices were added to a volume of $4^{\circ} \mathrm{KRP}$ equal to 10 times their weight and the fragments were dispersed using a pasteur pipette. The particulate brain suspension was kept on ice. After all of the brains for a particular experiment were prepared, they were stored on ice for $2 \mathrm{hr}$; this produced more consistent measurements of oxygen uptake. Each measurement utilized $50 \mathrm{mg}$ brain $(0.5-\mathrm{ml}$ suspension). This was added to $2.5 \mathrm{ml}$ of either KRP alone or KRP containing $5 \mathrm{~mm} \alpha$-D-glucose, the latter freshly prepared on the day of the experiment. After preincubation of the suspension in room air at $37^{\circ}$, the oxygen uptake was measured using the Clark electrode and a Beckman recorder. Temperature was maintained at $37^{\circ}$ by $\mathrm{K}-2 / \mathrm{R}$ circulator water bath (Brinkman Instruments, Westbury, NY). Each experiment consisted of four separate measurements of oxygen uptake using aliquots of one brain suspension in autoclaved glass vials: two measured uptake in KRP alone (endogenous metabolism), and two measured uptake with glucose. A baseline trace was obtained for KRP, KRP and glucose, and KRP with brain suspension in $4 \mathrm{~N}$ hydrochloric acid. All showed less than $1 \%$ uptake over 5 min. Results were calculated measuring the percent decrease in oxygen saturation per unit time with appropriate corrections for temperature, atmospheric pressure, the volume of suspension, and the amount of brain, and were expressed as $\mu$ moles $\mathrm{O}_{2}$ utilized per gram brain per hour.

To measure lactate production, slices of cortex were prepared as for measurement of oxygen uptake and placed in chilled KRP containing $2 \%$ glucose, through which carbon dioxide had been bubbled to displace dissolved oxygen. Brain suspension was incubated in flasks at $37^{\circ}$ in a metabolic shaker equipped with a hood through which flowed a mixture of $95 \%$ nitrogen and $5 \%$ carbon dioxide. Suspensions of brain were incubated in duplicate and the reaction was stopped by the addition of six drops of $4 \mathrm{~N}$ hydrochloric acid at $10,30,60$, and $120 \mathrm{~min}$. Lactate was measured enzymatically after centrifuging the suspensions at $5000 \times g$ using the method of Neville and Gelder (29). Lactate production was calculated by substracting the lactate present before incubation and expressed as $\mu$ moles of lactate produced per gram brain per unit time. 


\section{RESULTS}

After inoculation, rats with bacteremia had transient growth retardation that was maximal on the 3rd day (Fig. $1 B$ ). However, there was no difference between the brain weight of bacteremic animals in comparison to nonbacteremic rats until the 9th day after inoculation (Fig. 1 $A$ ). The brain dry weight to wet weight ratio failed to demonstrate brain edema (Fig. 2) during the meningitic period.

Mean blood concentrations of glucose, lactate, and BOHB in bacteremic and nonbacteremic rats were not significantly different (Table 1). In contrast, mean concentrations of brain glucose, lactate, and glycogen were significantly increased: at 2, 3, and 5 days for glucose and lactate and at 2 and 3 days for glycogen (Table 2) (all differences significant at $P<0.01$ ). However, the mean concentrations of brain ATP and BOHB were not significantly different $(P>0.01)$ from nonbacteremic animals. The volume of blood contained within frozen brain was not significantly different $(P>0.1)$ in rats with and without meningitis (Table 3).

Because our observations on the concentration of selected brain metabolites indicated that there was a significant increase in brain glucose (Table 2), subsequent studies were performed to measure the brain uptake of mannitol and 3-O-methylglucose. Five-dayold rats were inoculated intranasally with $H$. influenzae and 3 days later were injected ip with tracer doses of $\left[{ }^{3} \mathrm{H}\right]$ mannitol and 3-O[methyl- ${ }^{14} \mathrm{C}$ ]glucose. The rats were killed 90 min later. (Preliminary experiments were in agreement with Moore et al. (25), establishing that this time allowed stable serum concentrations of both mannitol and 3-O-methylglucose.) The brain uptake of both mannitol and 3-O-methylglucose was increased in rats with meningitis (Table 4).

A micropuncture technique was developed which permitted withdrawal of 20-30 $\mu \mathrm{l} \mathrm{CSF}$ from anesthetized rats. In rats with bacteremia exceeding $10^{4} / \mathrm{ml}$, CSF contained large numbers of inflammatory cells (mean $3800 / \mathrm{mm}^{3}$ ) and pleomorphic gramnegative rods (26). The mean CSF glucose concentration was higher in rats with meningitis compared to controls (Fig. 3). No differences were noted in the serum glucose concentrations of these rats immediately before micropuncture, a mean of $9.39 \pm$ $0.35 \mathrm{mM}$ for controls and a mean of $9.46 \pm 0.37 \mathrm{mM}$ for animals with meningitis.

Table 1. Serum concentration glucose, lactate, and $B O H B^{1}$

\begin{tabular}{lcc}
\hline & $\begin{array}{c}\text { Bacteremic, E-1 inocu- } \\
\text { lated }\end{array}$ & $\begin{array}{c}\text { Controls, U-11 inocu- } \\
\text { lated }\end{array}$ \\
\hline Glucose & $6.16( \pm 0.37)$ & $6.35( \pm 0.35)$ \\
Lactate & $1.56( \pm 0.25)$ & $1.41( \pm 0.23)$ \\
BOHB & $0.98( \pm 0.10)$ & $0.97( \pm 0.09)$ \\
\hline
\end{tabular}

${ }^{1}$ Mean $( \pm$ SEM) serum concentration $(\mathrm{mM})$ of 50 rats killed 1, 2, 3, 5, 7 , or 9 days (8-10 rats at each time) after inoculation with either $H$. influenzae $\mathrm{E}-1$ or $\mathrm{U}-11$.
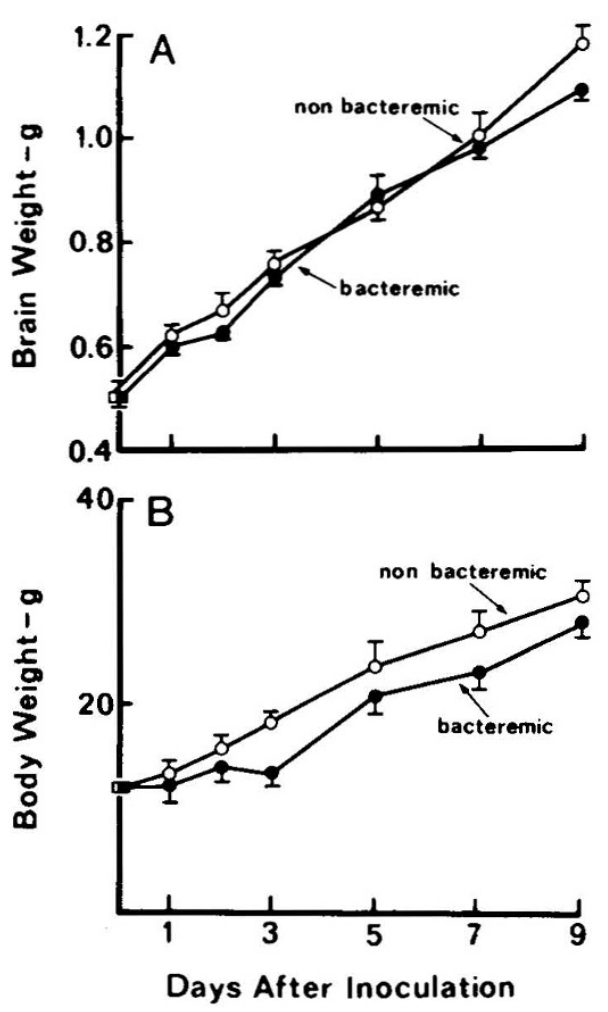

Fig. 1. Five-day-old rats were inoculated with $H$. influenzae strain E-1 (-) or U-11 (O) and killed at intervals thereafter. Each point represents the mean of 8-10 rats; vertical bars denote 1 SD from the mean. $A$, brain weight; $B$, body weight.

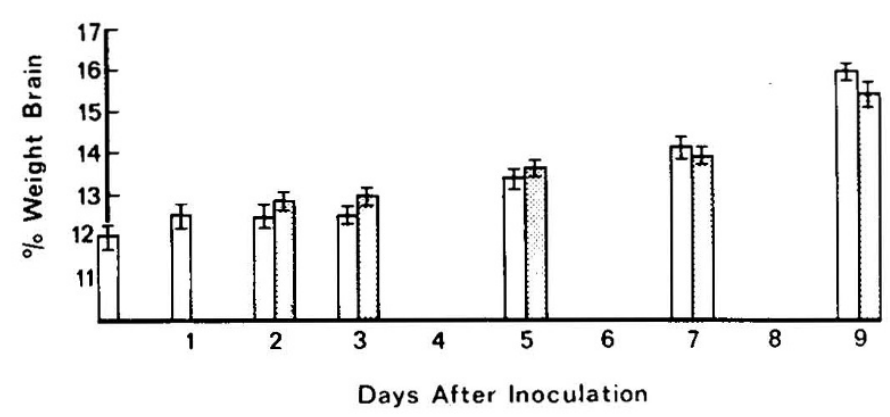

Fig. 2. Five-day-old rats were inoculated with $H$. influenzae $\mathrm{E}-1$ or $\mathrm{U}$ 11. Each bar represents the mean dry brain weight of 8-10 rats; light bars, nonbacteremic rats; dotted bars, bacteremic rats. Vertical bars denote 1 SD.

Table 2. Brain glucose, lactate, glycogen, $B O H B$, and $A T P^{1}$

\begin{tabular}{|c|c|c|c|c|c|c|c|c|c|c|}
\hline \multirow{2}{*}{$\begin{array}{l}\text { Time after inoc- } \\
\text { ulation (days) }\end{array}$} & \multicolumn{2}{|c|}{ Glucose } & \multicolumn{2}{|c|}{ Lactate } & \multicolumn{2}{|c|}{ Glycogen } & \multicolumn{2}{|c|}{ ВOHB } & \multicolumn{2}{|c|}{ ATP } \\
\hline & Bacteremic & Control & Bacteremic & Control & Bacteremic & Control & Bacteremic & Control & Bacteremic & Control \\
\hline 1 & $1.6(0.2)$ & $1.8(0.1)$ & $1.5(0.2)$ & $1.0(0.1)$ & $5.5(0.6)$ & $5.4(0.5)$ & $\mathrm{ND}^{2}$ & ND & $0.6(0.10)$ & $0.2(0.02)$ \\
\hline 3 & $2.7(0.2)^{3}$ & $1.6(0.2)$ & $2.7(0.3)^{3}$ & $1.2(0.2)$ & $5.7(0.2)^{4}$ & $3.5(0.9)$ & $0.4(0.1)$ & $0.4(0.1)$ & $0.8(0.08)$ & $0.9(0.06)$ \\
\hline 5 & $1.5(0.3)^{3}$ & $0.8(0.1)$ & $3.5(0.6)^{3}$ & $2.2(0.3)$ & $3.4(0.4)$ & $3.1(0.6)$ & ND & ND & $0.3(0.01)$ & $0.2(0.02)$ \\
\hline 7 & $1.4(0.3)^{4}$ & $0.8(0.1)$ & $2.8(0.5)$ & $2.1(0.2)$ & $2.7(0.3)$ & $2.2(0.6)$ & $0.3(0.1)$ & $0.3(0.1)$ & $0.4(0.02)$ & $0.4(0.01)$ \\
\hline
\end{tabular}

\footnotetext{
${ }^{1}$ Mean brain concentrations $( \pm$ SEM), lactate, glycogen, BOHB, and ATP in cerebral cortex of infant rats. Rats were challenged intranasally with $H$.
} influenzae and killed at 1, 2, 3, 5, 7, or 9 days. Values are reported as millimolar concentration per kilogram wet weight brain.

${ }^{2} \mathrm{ND}$, not done.

${ }^{3}$ Significantly different from controls, $P<0.01$.

${ }^{4}$ Significantly different from controls, $P<0.05$. 
The time elapsing from nembutal administration to collection of CSF averaged $3 \mathrm{~min}$; thus, we cannot exclude the possibility that rapid equilibration of serum and CSF glucose might have occurred.

Early experiments indicated a significant increase in brain glycogen concentration in meningitis (Table 2). To clarify this finding, seven 7-day-old rats who were bacteremic with $H$. influenzae $\mathrm{E}$ for $48 \mathrm{hr}\left(10^{4}-10^{5}\right.$ organisms $\left./ \mathrm{ml}\right)$ were killed. On light microscopy all seven bacteremic animals had meningitis; in contrast, sections of brain from rats without bacteremia revealed no abnormalities. Table 5 depicts brain glycogen concentration. Values were higher in rats with meningitis than in those without and the difference was significant $(P<0.05)$.

Electron microscopic examination of control rats demonstrated no histologic lesions in meninges or brain. The leptomeninges were composed of polygonal cells with fine interdigitating cytoplasmic processes forming a trabeculated subarachnoid space. The

Table 3. Volume of blood (microliters per gram brain) contained in frozen cortex of infant rats ${ }^{1}$

\begin{tabular}{cc}
\hline Meningitis & Control \\
\hline $145 \pm 68.0$ & $156 \pm 33$ \\
\hline
\end{tabular}

\footnotetext{
' Each value is the mean of measurements made on the frozen brains of four rats, 3 days after inoculation with $H$. influenzae E-1 or U-11.
}

Table 4. Brain uptake of $\left[{ }^{3} \mathrm{H}\right]$ mannitol and 3-O-[methyl- $\left.{ }^{14} \mathrm{C}\right]$ glucose $^{1}$

\begin{tabular}{lcc}
\hline & {$\left[{ }^{3} \mathrm{H}\right]$ mannitol } & $\begin{array}{c}3-O-\left[\text { methyl }{ }^{14} \mathrm{C}\right] \text { glu- } \\
\text { cose }\end{array}$ \\
\hline $\begin{array}{l}\text { Brain } \\
\quad \text { Meningitis }\end{array}$ & $2.5( \pm 0.31) \times 10^{3}$ & $1.8( \pm 0.23) \times 10^{5}$ \\
$\quad$ Control & $1.4( \pm 0.30) \times 10^{3}$ & $1.1( \pm 0.08) \times 10^{5}$ \\
Serum & & \\
$\quad$ Meningitis & $10.00( \pm 1.67) \times 10^{4}$ & $4.3( \pm 1.35) \times 10^{5}$ \\
$\quad$ Control & $11.60( \pm 2.33) \times 10^{4}$ & $3.2( \pm 1.09) \times 10^{5}$ \\
Ratio (brain/serum) & & \\
$\quad$ Meningitis & $0.025^{2}$ & $0.42^{3}$ \\
$\quad$ Control & 0.012 & 0.34 \\
\hline
\end{tabular}

' Rats were injected ip with tracer doses of labeled $\left[{ }^{3} \mathrm{H}\right]$ mannitol or 3 $O-\left[\right.$ methyl $\left.-{ }^{14} \mathrm{C}\right]$ glucose and killed $2 \mathrm{hr}$ later. Serum and brain values are mean $( \pm S D)$ of nine rats. Results expressed as disintegrations per minute per milliliter blood or per gram wet weight brain.

${ }^{2}$ Significantly different from controls, $P<0.01$.

${ }^{3}$ Significantly different from controls, $P<0.05$.

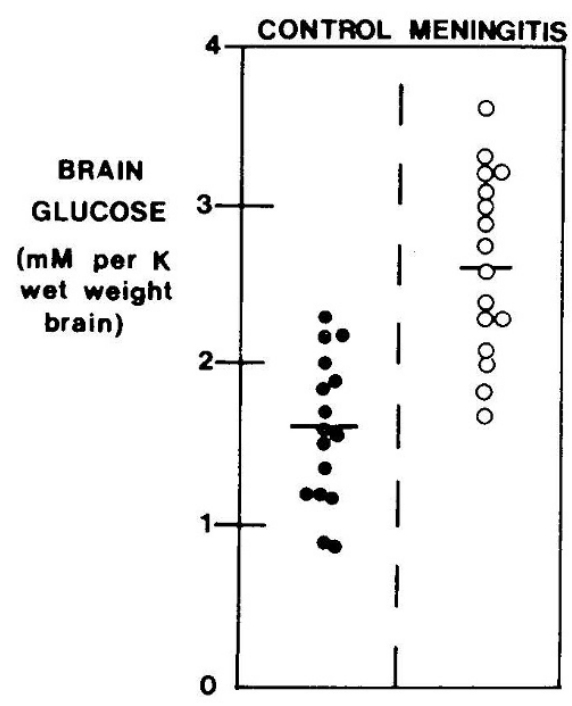

pia mater was formed of a single cell layer immediately overlying a continuous basement membrane. The subpial nervous tissue was composed of electron-dense astroglial foot processes containing glial fibrils. The neuropile and other cellular components of cortical layers I through III were well preserved and had no ultrastructural abnormalities. The subarachnoid space contained an occasional macrophage with irregularly arranged pseudopodia, pinocytotic vesicles, numerous clear vacuoles, and electron-dense cytoplasmic inclusions. Glycogen was rarely present in subpial astrocytic foot processes.

In rats with meningitis on light microscopy, the subarachnoid space was filled with polymorphonuclear and mononuclear leukocytes. The mononuclear cells resembled subarachnoid macrophages. The polymorphonuclear leukocytes contained large masses of electron-dense particles consistent with glycogen (Fig. 4 ) and had reduced numbers of cytoplasmic granules. Occasional glycogen-laden polymorphonuclear leukocytes were found in cortical layers I and II (Fig. 5).

Glycogen granules were two to three times more abundant in the subpial and perivasicular astroglial foot processes of meningitic rats compared to controls. No glycogen particles were found in developing synaptic terminal axons, dendritic ramifications, astroglial or neuronal perikarya, endothelial cells, or pericytes.

Suspension of brain slices, prepared from bacteremic rats $\left(>10^{4}\right.$ colony-forming units $/ \mathrm{ml}$ ) and controls were not significantly different in their rate of oxygen consumption or anaerobic lactate production (Fig. 6 and 7).

Table 5. Brain glycogen concentration in infant rats inoculated with $H$. influenzae ${ }^{\mathrm{I}}$

\begin{tabular}{cccc}
\hline Animal & $\begin{array}{c}\text { Brain glyco- } \\
\text { gen }\end{array}$ & $\begin{array}{c}\text { No. bacteria/ml } \\
\text { blood }^{2}\end{array}$ & $\begin{array}{c}\text { Presence (+) or absence } \\
(-) \text { of meningitis }\end{array}$ \\
\hline 1 & 3.13 & 0 & - \\
2 & 4.64 & $10^{4}$ & + \\
3 & 3.27 & $10^{4}$ & + \\
4 & 2.70 & 0 & - \\
5 & 4.00 & $10^{5}$ & + \\
6 & 3.54 & $10^{4}$ & + \\
7 & 5.31 & $10^{5}$ & + \\
8 & 4.69 & $10^{4}$ & + \\
9 & 4.82 & $10^{4}$ & - \\
10 & 2.96 & 0 & + \\
\hline
\end{tabular}

\footnotetext{
' Results expressed as millimolar concentration per kilogram wet weight brain.
}

${ }^{2}$ Based on culture of $10 \mu \mathrm{l}$ blood obtained at the time of killing.

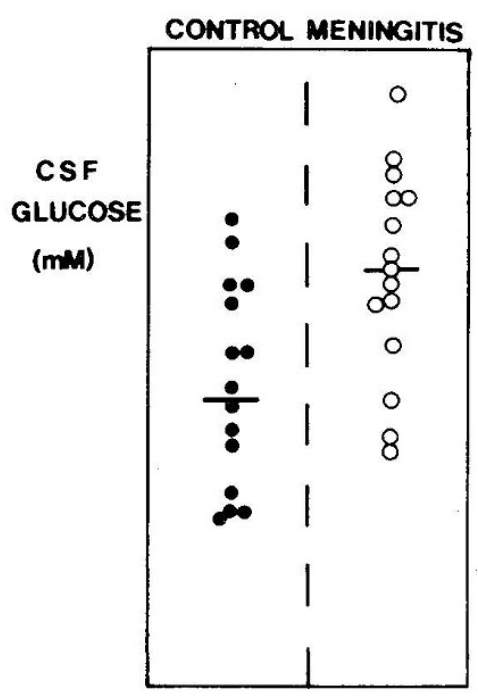

Fig. 3. Brain and CSF glucose concentrations in rats with $(\bigcirc)$ and without $(\bullet)$ meningitis. Five-day-old rats were killed 3 days after inoculation with H. influenzae. Horizontal bars indicate the mean. 


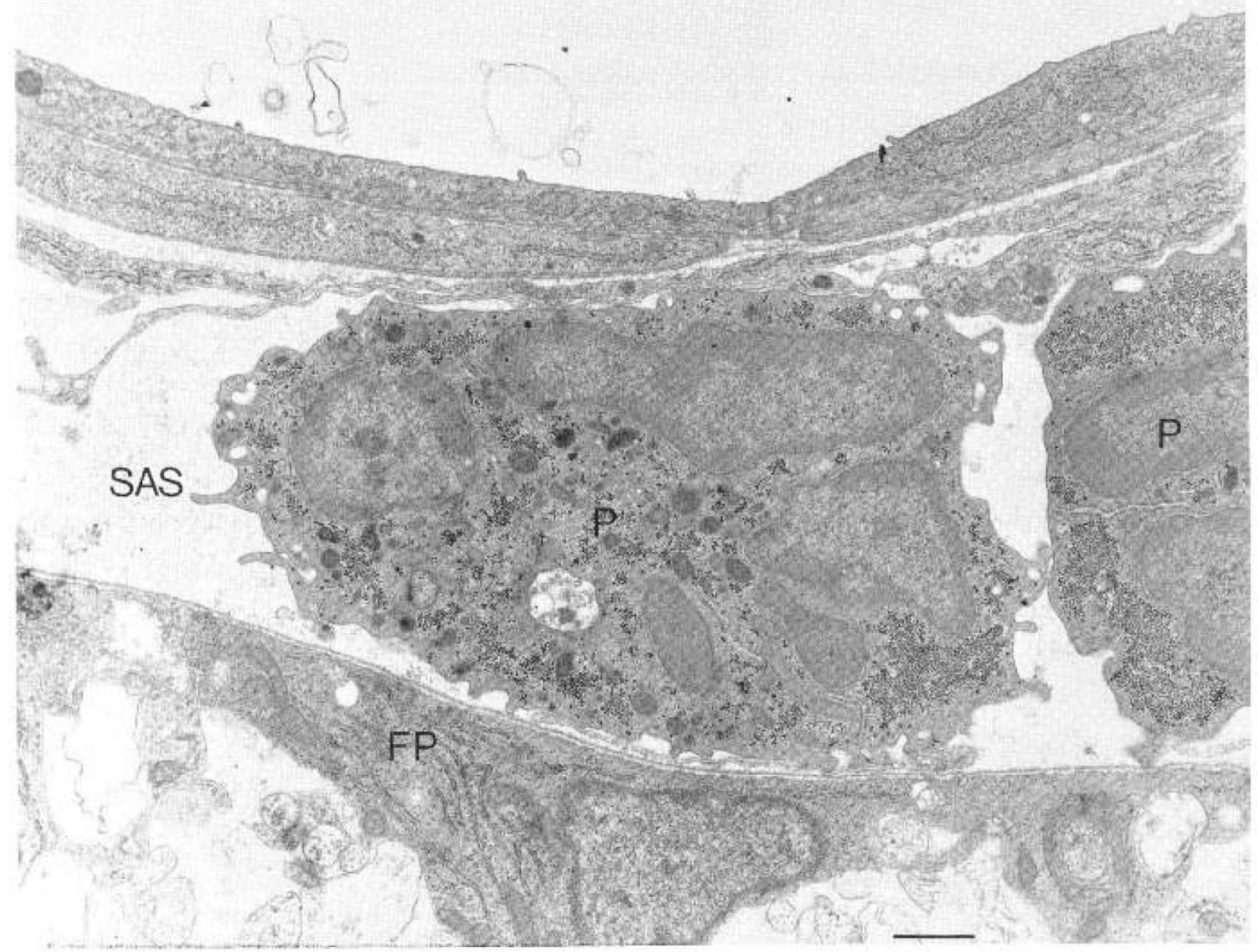

Fig. 4. Two polymorphonuclear leukocytes (P) within the subarachnoid space (SAS) immediately overlaying an astroglial foot-process (FP) within the neuropile of cortical layer I. Material is from a 7-day-old rat $48 \mathrm{hr}$ after inoculation. Note granular proteinaceous material in SAS and large clumps of glycogen granules in P cytoplasm. Horizontal bar is $1 \mu$.

\section{DISCUSSION}

Bacterial meningitis could damage the brain by a number of mechanisms: bacteria might exert a direct effect or the inflammatory response may secondarily damage cerebral tissue. In humans and rats, bacteria rarely penetrate the outermost layer of the cortex and are confined to the meninges. Meningeal infection could affect the brain through diffusion of toxins or other products released from bacteria or inflammatory cells (12). A decrease in cerebral blood flow (localized or generalized) might result in altered perfusion of brain and compromised delivery of oxygen and/or essential substrates (e.g., glucose). Finally, systemic disturbances far removed from brain itself might 1 esult in impaired efficiency of vital organ function, such as heart or liver, causing changes in the perfusion or concentration of important nutrients delivered to brain.

Using the infant rat model, the hypothesis that $H$. influenzae meningitis causes alterations in cerebral carbohydrate metabolism was examined. This hypothesis has been advanced to explain hypoglycorrachia (23). Convincing evidence to support this contention was not found. Brain glucose, lactate, and glycogen concentrations were increased in rats with meningitis, but there was no reduction in brain ATP concentration. Oxygen consumption and lactate production by brain slices from rats with meningitis were similar to controls.

These findings must be judged in the light of the unexpected finding that CSF glucose concentration in rats with meningitis was not decreased-an observation which contrasts with the welldocumented hypoglycorrachia observed in humans (23) and dogs (32) with untreated bacterial meningitis.

However, in normal newborn human infants the CSF glucose concentration overlaps with that from neonates with pyogenic meningitis (37). Thus, the newborn human and the infant rat may have similarities in their cerebral metabolic response to infection. This similarity might be that both the infant rat $(9,17)$ and the human newborn (20) brain can use BOHB and acetoacetate as an alternative oxidizable substrate. It has been estimated that the rate of glucose utilization of the infant rat brain is $10 \%$ of the adult capacity. Thus, with a "decreased demand" on the glucose delivered to the brain in infants, a derangement of glucose transport might not be observed. Although this suggestion might explain the lack of hypoglycorrachia, it does not explain the increased CSF glucose concentration.

Increased brain uptake of mannitol and 3-O-methylglucose occurred in rats with meningitis. Because neither are metabolized, we assume that such increases reflect an increased concentration 


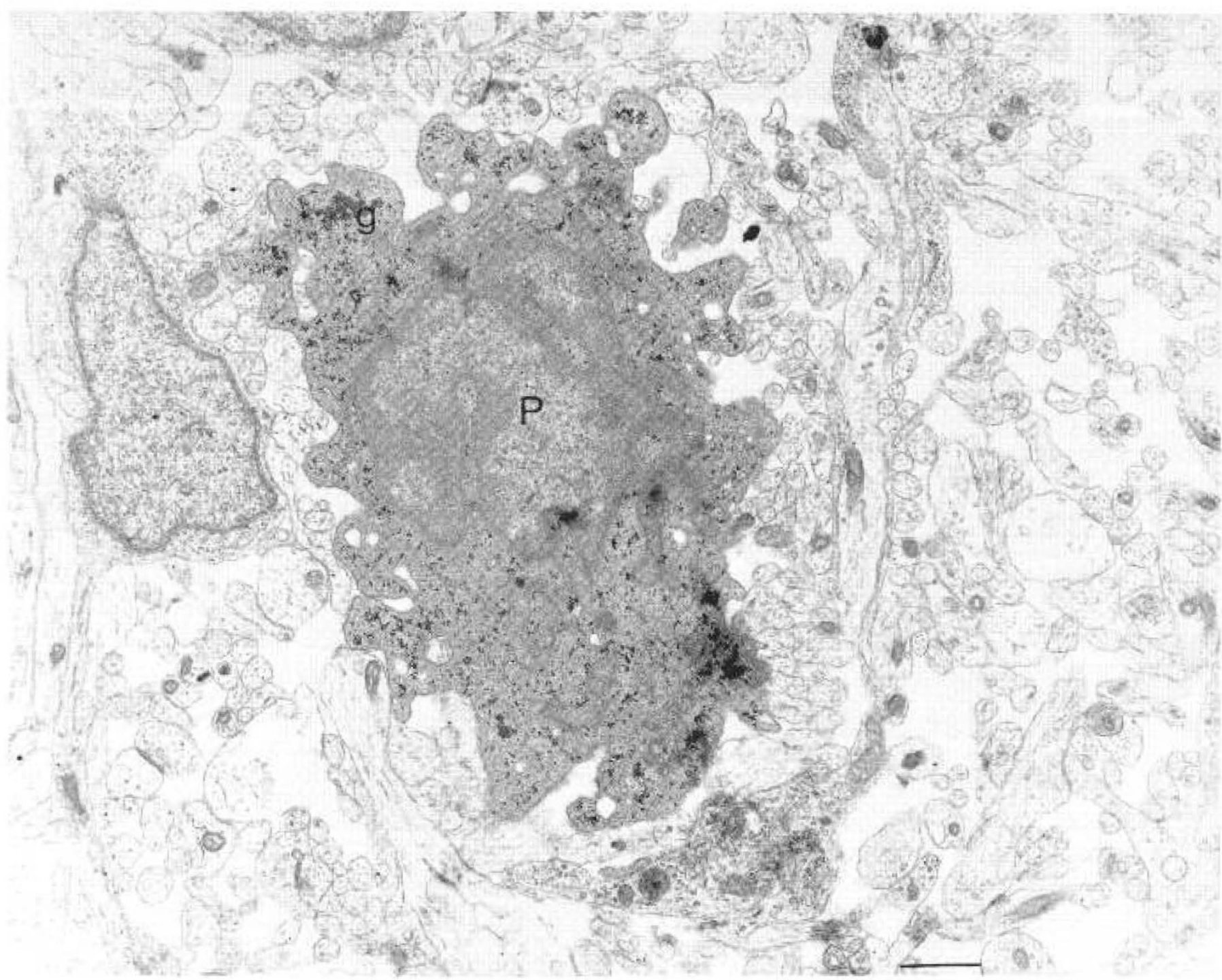

Fig. 5. Cerebral cortical layer I from a 7-day-old rat $48 \mathrm{hr}$ after inoculation. A solitary polymorphonuclear leukocyte (P) is present containing clumps of glycogen granules $(\mathrm{g})$. Horizontal bar is $1 \mu$.

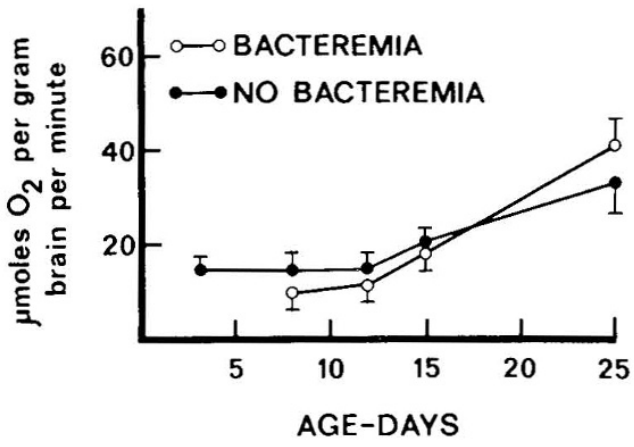

Fig. 6. Rate of glucose-dependent oxygen consumption of cerebral cortical suspensions derived from rats inoculated at 5 days of age with strain U-11 or E-1. Each point represents the mean of 8-10 animals; vertical bars indicate $1 \mathrm{SD}$. Bacteremia, when it occurs, persists for 10-12 days.

within the brain extracellular space or an alteration in the volume of distribution of glucose. We were not able to explain these findings on the basis of increased blood trapped in the brains of infected rats, or on the basis of brain edema as estimated by wet

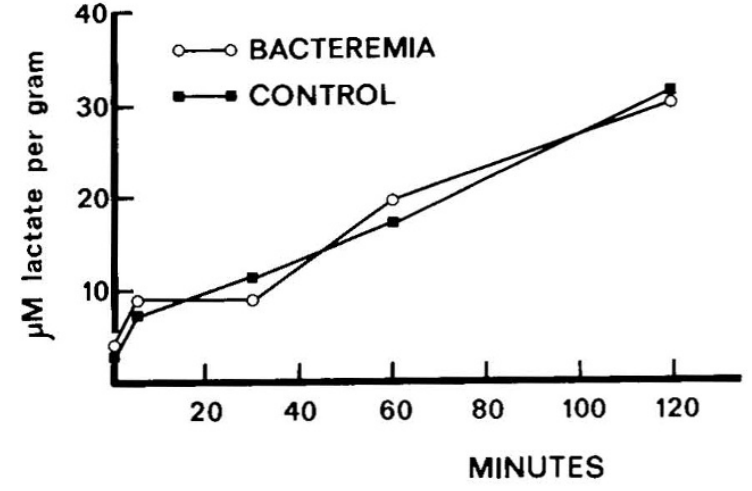

Fig. 7. Lactate production by cerebral cortical slices derived from 7day-old infant rats. Those bacteremic have been so for 14-18 hr. Glucose $(5 \mathrm{mM})$ was the substrate under anaerobic conditions at $37^{\circ}$. Each point represents mean of 8-10 animals.

weight to dry weight ratios. This latter finding was surprising inasmuch as cerebral edema has been observed in $60 \%$ of human cases of acute bacterial meningitis (45). However, cerebral edema may selectively involve white matter (46); thus, the low meylin content of immature rat brain may prevent excessive water accumulation. 


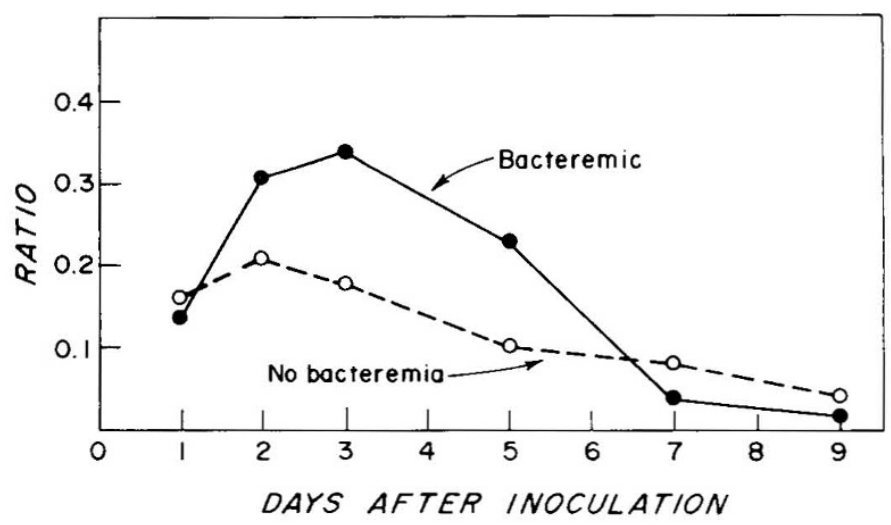

Fig. 8. Ratio of mean brain-blood glucose concentration of infant rats inoculated at 5 days of age with strain U-11 (no bacteremia) or E-1 (bacteremic). Brain concentration is highest 2-5 days after inoculation.

Prockop and Fishman previously reported alterations in the blood to CSF transport of a nonmetabolizable glucose analogue in dogs with pneumococcal meningitis (35). These studies concluded that acute meningitis resulted in decreased carrier-mediated transport of glucose from blood to CSF, but there was an accompanying increase in glucose diffusion. Because glucose entry occurs predominately by the carrier-mediated mechanism, the observations were consistent with the observed decrease in CSF glucose concentration. In the present study, brain and CSF glucose concentrations were increased in infant rats with meningitis (Fig. 8). Our observation of an increased diffusion of $\left[{ }^{3} \mathrm{H}\right]$ mannitol might account for the observed increase in brain and CSF "free" glucose concentrations in meningitic rats, i.e., a markedly increased inward diffusion. This suggests that there was a generalized increase in the permeability of the blood-brain barrier, permitting entry of both hexoses. Thus, the increased CSF glucose concentration in meningitic rats may be the result of increased diffusion. Breakdown of the blood-brain barrier occurs after the administration of Escherichia coli endotoxin. Because $H$. influenzae also contains endotoxin, the dense infection of blood and meninges might result in endotoxin concentrtion high enough to have a pharmacologic effect. In addition, the substantially slower utilization of glucose by the infant rat could minimize the effect of any reduction in carrier-mediated transport (25).

Increased brain lactate concentration is also found in cortical tissue subjected to anoxia (44) or hyperthermia (2); both are situations in which the brain is thought to have switched from oxidative phosphorylation to anaerobic glycolysis. Our studies demonstrated that cerebral cortical tissue derived from animals with meningitis consumed oxygen and produced lactate at rates equivalent to controls; this suggests functional integrity of the mitochondria and the cytosol. The increased CSF lactate observed in humans with pyogenic meningitis is roughly proportional to the severity of the disease $(6,19)$. The source of CSF lactate is thought to be the brain itself as blood and CSF lactate are not interdependent (34). Thus, the increased brain lactate content seen in this study and the increased CSF lactate content in humans suggest that meningitis effects a diversion of brain glucose to anaerobic glycolysis. This might be due to a deficiency of some other substrate of oxidative metabolism (e.g., oxygen), as the tissue functions equivalent to controls in vitro. Proof of the diversion hypothesis requires measurement of cerebral blood flow, cerebral metabolite extraction (production) rates, and lactate appearance in the CSF. This would facilitate calculation of a "balance sheet" accounting for glucose consumed and lactate produced. Implicit in this hypothesis, on the basis of our data, is the fact that glucose flow through the glycolytic pathway is increased enough to maintain "normal" brain ATP concentrations.

An alternative explanation is that CSF lactate accumulation is the result of phagocytosis by macrophages and polymorphonu- clear leukocytes. The magnitude of the increase makes this suggestion seem unlikely: $10^{6}$ granulocytes produce $0.05 \mu \mathrm{mol} \mathrm{lac}$ tate/hr $(8,11)$. We have previously found that there are $10^{5}-10^{7}$ intracranial polymorphonuclear leukocytes in infant rats with meningitis (41). If we assume that CSF volume of an infant rat is $150 \mu \mathrm{l}$, and the brain tissue volume is $500 \mu \mathrm{l}$, then the total intracranial volume is $650 \mu \mathrm{l}$. If the cerebral lactate is in equilibrium with CSF, then the total brain and CSF lactate content is $2.63 \mu \mathrm{mol}$. Thus, leukocytes could not generate enough lactate to yield an intracranial concentration of $2.63 \mu \mathrm{mol}$ unless they were present for $52.6 \mathrm{hr}$. In other sites, such as a skin window, the halflife of the polymorphonuclear leukocyte is $2-4 \mathrm{hr}$. Thus, for cellular inflammatory infiltrate to increase the brain and CSF lactate concentration, the cells would have to be viable longer in the meninges than elsewhere.

Significant increases in brain glycogen were observed in rats with meningitis; similar observations have been reported by others following other types of cerebral insult $(21,28)$. However, some of the observations on human autopsy material used nonspecific staining methods. In addition, there is contradiction as to the precise localization of this glycogen: Friede reported glycogen in perivascular spaces and surrounding brain tissue (13), whereas Munzer and Oksche thought that glycogen could be detected in nerve cells $(28,30)$. In the present study, increased glycogen content was verified with an enzymatic assay and localized by electron microscopy. The glycogen accumulations were contained within polymorphonuclear leukocytes in the subarachnoid space, infiltrating the superficial layers of the cortex and within glial foot processes at the pial surface. In a previous study, the intensity of the cellular infiltration in rats with meningitis was quantitated and ranged from $10^{5}-10^{7}$ polymorphonuclear leukocytes per gram brain (41). Because actively phagocytosing polymorphonuclear leukocytes contain $0.6-0.3 \mu \mathrm{g}$ glycogen per $10^{\prime}$ cells $(47)$, the observed differences in brain glycogen content between rats with and without meningitis are consistent with the calculated quantity of glycogen contained in $10^{7}$ polymorphonuclear leukocytes per gram infected brain. These findings are of interest in that increased brain glycogen has been reported after irradiation injury $(24,48)$ and surgical brain wounds $(18,39)$ and attributed to disturbances in brain metabolism. However, in none of these studies was the possible contribution of glycogen by inflammatory cells discussed.

In summary, these studies suggest that abnormalities of carbohydrate metabolism are not associated with a change in ATP content; thus, they are unlikely to account for the altered responses in operant conditioning (42) or delayed neuronal growth (5) described in rats surviving untreated $H$. influenzae meningitis. We did not observe hypoglycorrachia, possibly related to the low glucose consumption and alternative energy pathways of immature rat brain.

Finally, the CSF of infant rats contained numerous white cells and bacteria, but was associated with increased CSF glucose concentrations. This finding provides further evidence that hypoglycorrachia is not likely the result of consumption of glucose by bacteria and inflammatory cells (23).

\section{REFERENCES AND NOTES}

1. Alexander, H. E.: Hemophilus influenzae. In: R. J. Dubos: Bacterial and Mycotic Infections of Man. p. 470 (J. B. Lippincott Co.. Philadelphia. 1958)

2. Alexander, S. C.. Workman. R. D.. and Lambersten. C. J.: Hyperthermia. lactic acid infusion and the composition of arterial blood and CSF. Am. J. Physiol.. 202: 1049 (1962).

3. Anderson. P.. Johnston. R. B.. Jr.. and Smith. D. H.: Human serum activities against Hemophilus influenzae type b. J. Clin. Invest.. 51: 31 (1972).

4. Antonis. A., Clark. M.. and Pilkington. T. R. E.: A semi-automated fluorometric method for the enzymatic determination of pyruvate. lactate. acetoacetate and $\beta$-hydroxybutyrate levels in blood. J. Lab. Clin. Med.. 68: 340 (1966).

5. Averill. D. R., Moxon. E. R.. and Smith. A. L.: Effects of Hemophilus influenzae meningitis in infant rats on neuronal growth and synaptogenesis. Exp. Neurol.. 50: 337 (1976).

6. Bland, R. D., Lister, R. C., and Ries. J. P.: Cerebrospinal fluid lactic acid level and $\mathrm{pH}$ in meningitis. Am. J. Dis. Child., 128: 151 (1974).

7. Cheer, S.. Gentile, J. H.. and Hegre. C. S.: Improved methods for ATP analysis. Anal. Biochem.. 60: 102 (1974). 
8. Cline. M. J.: Metabolism of the circulating leukocyte. Physiol. Rev., 45: 674 (1965).

9. DeVivo, D. C., Lecki, M. P.. and Agrawal, H. C.: D- $\beta$-hydroxybutyrate: A major precursor of amino acids in developing rat brain. J. Neurochem., 25: 161 (1975).

10. Drabkin, D. L.: In: O Glasser: Photometry and Spectrophotometry in Medical Physics, Vol. 1 (Yearbook Medical Publishers, Chicago, 1944).

11. Esmann, V.: The diabetic leukocyte. Enzyme (Basel), 13: 32 (1972).

12. Fishman, R. A., Sligar, K., and Hake, R. B.: Effects of leukocytes on brain metabolism in granulocytic brain edema. Ann. Neurol., 2: 89 (1977).

13. Friede, R. L.: Topographic Brain Chemistry, p. 139 (Academic Press, New York, 1966).

14. Gordon, M. W., and Nurnberger, J. I.: A method for the rapid estimation of whole blood in homogenized tissue preparations. J. Histochem. Cytochem., 3: 130 (1955).

15. Gordon, M. W., and Nurnberger, J. I.: Estimation of whole blood in tissue homogenates. J. Histochem. Cytochem., 4: 84 (1956).

16. Haggerty, R. J., and Ziai, M.: Acute bacterial meningitis. Adv. Pediatr., 13: 129 (1964)

17. Hawkins, R. A., Williamson, D. H. and Krebs, H. A.: Ketone-body utilization by adult and suckling rat brain in vivo. Biochem. J., 122: 13 (1971).

18. Haymaker, W., Miquel, J., and Ibrahim, M. Z. M.: Glycogen accumulation following brain trauma. Top. Probl. Psychiatry Neurol., 10: 71 (1970).

19. Kopetzsky, S. J., and Fishberg, E. H.: Changes in distribution of constituents of blood and spinal fluid in meningitis. J. Lab. Clin. Med., 18: 796 (1932-33).

20. Kraus, H., Schlenber, S., and Schwedesky, D.: Developmental changes of cerebral ketone body utilization in human infants. Hoppe-Seyler's Z. Physiol. Chem. 355: 164 (1974).

21. Marinesco, G.: Sur le presence et les variations due glucogene dans le neraxe et les glandes endocrines (A l'etat normal et pathologique). Ann. Anat. Pathol. Medico-chivugicale., 5: 233 (1928).

22. McIlwain, H., and Rodnight, R. (eds): Practical Neuro-Chemistry (Churchill Publishers, London, 1962).

23. Menkes, J. H.: The causes for low spinal fluid sugar in bacterial meningitis: Another look. Pediatrics, 44: 1 (1969).

24. Miquel, J., and Haymaker, W.: Glycogen accumulation in monkey and cat brain exposed to proton irradication. Proceedings of the 5 th International Conference on Neuropathology (Excerpta Medica Foundation, Amsterdam, 1966).

25. Moore, T. J., Lione, A. P., Regen, D. M., Tarpley, H. L., and Raines, P. L.: Brain glucose metabolism in the newborn rat. J. Physiol. (Lond.), 221: 1746 (1971)

26. Moxon, E. R., and Ostrow, P. T.: Haemophilus influenzae in infant rats: The role of bacteremia in the pathogenesis of the age-dependent inflammatory responses in cerebrospinal fluid. J. Infect. Dis., 135: 303 (1977).

27. Moxon, E. R., Smith, A. L., Averill. D. R., and Smith, D. H.: Haemophilus influenzae meningitis in infant rats after intranasal inoculation. J. Infect. Dis., 129: 154 (1974)

28. Munzer, F. T.: Uben Dorstellung und Vorkommen von Glykogen im Nervensystem. Zentralbl. Gesamte Neurol. Psychiat., 112: 288 (1928).

29. Neville, J. F., and Gelder, R. L.: Modified enzymatic methods for the determination of $\mathrm{L}(+)$ lactic and pyruvic acid in blood. Am. J. Clin. Path., 55: 152 (1971).

30. Oksche, A.: Quoted in R. L. Friede: Topographic Brain Chemistry, p. 142 (Academic Press, New York, 1966).
31. Passonneau, J. V., Gatfield, P. D., Schule, D. W., and Lowry, O. H.: An enzymatic method for measurement of glycogen. Anal. Biochem., 19: 315 (1967).

32. Petersdorf, R. G., Swarner, D. M., and Garcia, M.: Studies on the pathogenesis of meningitis. III. Relationship of phagocytosis to the fall in cerebrospinal fluid sugar in experimental pneumococcal meningitis. J. Lab. Clin. Med., 61: 745 (1963).

33. Phillips, R. E., and Elevitch, F. F.: An enzymatic fluorometric method for determination of glucose in plasma. Am. J. Clin. Path., 45: 622 (1968).

34. Posner, J. B., and Plum, F.: Independence of blood and cerebrospinal fluid lactate. Arch. Neurol., 16: 492 (1967).

35. Prockop, L. D., and Fishman, R. A.: Experimental pneumococcal meningitis permeability changes influencing the concentration of sugars and micromolecules in cerebrospinal fluids. Arch. Neurol., 19: 449 (1968).

36. Rhodin, J. A. G.: In: Histology, p. 46 (Oxford University Press, New York, 1974).

37. Sarff, L. D., Platt, L. H., and McCracken, G. H.: Cerebrospinal fluid evaluation in neonates: Comparison of high risk infants with and without meningitis. J. Pediatr., 88: 473 (1976).

38. Deleted in proof.

39. Schimizu, N., and Hamuro, Y.: Deposition of glycogen and changes in some enzymes in brain wounds. Nature (Lond.), 181: 781 (1958).

40. Sell, S. H. W., Merrill, R. E., Doyne, E. O., and Zimsky, E. P.: Long-term sequelae of Hemophilus influenzae meningitis. Pediatrics, 49: 206 (1972).

41. Smith, A. L., Rosenberg, I., Averill, D. R., Moxon, E. R., and Smith, D. H.: Brain polymorphonuclear leukocyte quantitation by peroxidase assay. Infect. Immun., 10: 356 (1974)

42. Deleted in proof.

43. Sproles, E. T., Azerrad, J., Williamson, C., and Merrill, R. E.: Meningitis due to Hemophilus influenzae: Long-term sequelae. J. Pediatr., 75: 782 (1969).

44. Svenningsen, N. W., and Siesjo, B. K.: Cerebrospinal fluid lactate/pyruvate ratio in normal and asphyxiated neonates. Acta Paediatr. Scand., 75: 782 (1969).

45. Swartz, M. N., and Dodge, P. R.: Bacterial meningitis-a review of selected aspects. N. Engl. J. Med., 272: 725 (1965).

46. Tower, D. B.: Cerebral edema. In: R. W. Albers, G. J. Siegel, R. Katzman, and B. W. Agranoff: Basic Neurochemistry, p. 537 (Little Brown and Co., Boston, 1972).

47. Wagner, R.: The estimation of glycogen in whole blood and white blood cells. Arch. Biochem. Biophys., 11: 249 (1946).

48. Wolfe, L. S., Klatzo, I., Miquel, J., Tobias, C., and Haymaker, W: Effect of alpha-particle irradiation on brain glycogen in the rat. J. Neurochem., 9: 213 (1962).

49. The authors thank Dr. David H. Smith and Dr. Porter Anderson for advice, Ms. Anne Jacobson and Mr. Robert Kapko for technical assistance, and Mr. Walter Siedlecki and Ms. Nancy Croghan for secretarial assistance.

50. This research was supported in part by Grants NS 09048 and NS 122554 from the National Institutes of Health and in part by the Hospital for Consumptives of Maryland (Eudowood), Baltimore, Md.

51. Requests for reprints should be addressed to: E. Richard Moxon, Department of Pediatrics, Johns Hopkins Hospital, 601 N. Broadway, Baltimore, MD 21205 (USA).

52. Received for publication December 30, 1977

53. Accepted for publication March 13, 1978. 